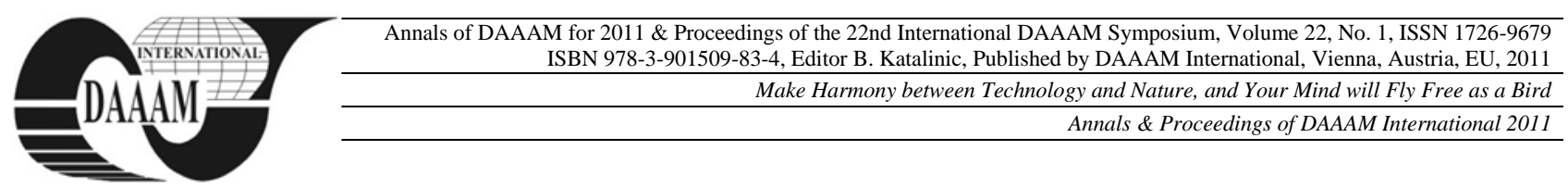

\title{
INNOVATION AND TEN SUCCESS FACTORS IN ENGINEERING INDUSTRY
}

\author{
VIDENOVA, V[eronika]; KRAJCOVICOVA, K[atarina] \& SABLIK, J[ozef]
}

\begin{abstract}
The authors argue that the nature and importance of innovative change in automotive industry began to alter and grew in importance. According the authors this article is important the structure of innovation management. This structure consists of 3 elements and relationships between them - Methodology, Management innovation activities and Management innovation behavior. The authors shows on ten success factors for industrial innovation will have higher living standards and industrial employment than those without.
\end{abstract}

Key words: innovation, innovation strategy, competitiveness, automotive industry

\section{INTRODUCTION}

Innovations are all around us and a significant applied in industrial plants. In Slovakia is currently seen the greatest progress of innovation in the automotive industry for last years.

The growing role of innovation in the strategy of car manufacturers leads them to relentlessly look for new sources of differentiation. In the automotive industry management must carefully consider in advance the investment strategy for the next horizont.

The greatest potential for innovation for the automotive industry is the competitiveness, which constantly encourages continuous innovation process. Enterprises are being forced to innovate to maintain current market position.

\section{WHAT IS THE INNOVATION?}

Innovations are a set of activities leading to progress not only in the production process, but also social, economic and environmental spheres.

Innovations spread vertical and horizontal way, vertical involves obtaining information from universities, scientific research centers of the country. Horizontal method from the vertical method differs in that the flow of information is drawn primarily from foreign research.

The modern automotive industry is characterized by low vertical integration in the manufacturing process and high level of integration of producers and suppliers. Slovak automotive industry applies only way - horizontal integration of innovation. Automotive manufacturers and their suppliers should have a goal to offer innovative products at competitive prices across the world market. According to many authors, expert studies suggest a growing share of electric and electronic systems in vehicles (Bessant et al.,2007).

Company Mercer Management Consultants and HYPOVEREINSBAK draw up a list of the main points of technological change to the 2015:

- 1 st increasing the share of electrical and electronic components,

- 2nd alternative access control systems,

- 3rd increasing use of innovative materials,

- 4th changes in production technology,

- 5th expansion of software functions car (Wyman, 2011).
The human potential ssignificantly contributes to the formation of Innovation Company. Therefore, enterprises should carefully consider the potential of their employees, know them and turn into real results and performances that will benefit their business. The aim of business is to get the maximum work from employees as possible.

According the authors this article is important the structure of innovation management. This structure consists of 3 elements and relationships between them:

- Methodology for preparation and implementation of innovation in terms of procedures, methods and techniques processing and implementation of complex innovation processes. The most popular methodological guidelines to ensure the prosperity of the organization include, for example: Kaizen, Lean Production (Lean), Just in time, Benchmarking, Reengineering and etc.

- Management innovation activities, which are the product of power management, functions, that a manager performs. These are activities that are directly related to the preparation, design and implementation of innovative activities. Terms of planning, organizing, selecting and deployment of employees, motivating and controlling.

- Management innovation behavior in the form of highly developed human creative activity managers. In the first place is for managers at all levels of expected change invention to innovation. Knowledge and qualifications of managers at all levels management should be a guarantee of technical assistance teams to transform their ideas into real concrete proposals. These skills should be so intense that executives could also attract the interest of other workers (Košturiak \& Chál', 2008).

\section{TEN SUCCESS FACTORS}

Lot of authors are writing about innovations and various method how should to help to keep the place on market or get a new more effective place on world market. According the authors this article is very important for success on market following ten factors. This factors show what is necessary for effective competitiveness in automotive industry.

\subsection{Innovation proposition}

Technological vision: Top performers constantly scan their environment for long term trends in the market and in technologies. They develop a long-term innovation vision and stick to it, no matter what the short-term trends are

Customer knowledge: Understanding customer preferences enables companies to better focus their innovation efforts on relevant issues. Customer research needs both a regional and a socio-demographic approach to be of value.

Strategy match: Successful OEMs (Original equipment manufacturer) and suppliers match their $R \& D$ strategies at a very early stage, and very closely with the respective target OEM or supplier partner. This is especially true when the car architecture is affected, i.e. with module innovations. 


\subsection{Competence focus \& collaboration}

Competence focus: The best innovators closely match their $R \& D$ competencies with their R\&D strategy. OEMs and bigger suppliers with a diversified product range must continuously recalibrate their competencies to their strategic $R \& D$ targets.

Strategic partners: With their increasing complexity, R\&D networks are becoming a crucial success factor. Currently, it is mostly OEMs that are forming such networks. In the future, supplier-supplier and supplier-institution collaborations will increase.

\subsection{Business case}

Investment focus: $R \& D$ funding must be independent of current business needs. In the past, short-term changes in the R\&D focus have often led to long-term problems. Catching up with past $R \& D$ cuts has often proven to be extremely expensive.

Trend focus: Relying on megatrends contributes significantly to the soundness of $R \& D$ investments, as these trends are highly predictable. Interpreting these trends in terms of a company's own business model is a main conceptual challenge for automotive companies.

Cost focus: Leaders in innovation always have a strong cost focus, with respect to R\&D efficiency and effectiveness. Regardless whether it is a single component or an entire car, the reduction of unit costs is the center of their innovation efforts.

\subsection{Organization \& culture}

Outside-in strategy: Top performers concentrate on innovations that the market needs and end low-value projects early. Processes that strengthen this ability are a common understanding of innovation aims within the company and a standard quality process.

People involvement: Companies that involve people from all levels in their $R \& D$ are much more successful innovators. The keys to employee involvement are easy and motivating communications, low hurdles for submission of ideas, and efficient and transparent filters for the incoming ideas.

Many of these success factors are important for automotive industry. According to the authors, it can apply these success factors in others part of industry, not only automotive. It will be necessary to research these factors more deep in the future and prepare them in the suitable form for every industry.

\section{AREAS OF ACTION FOR INNOVATION MANAGERS}

There are five areas of action to improve innovation management in the automotive industry.

\subsection{Stronger focus on customers and marketing}

Innovations can succeed only if they address megatrends, legislation, competition or the customer. The majority of today's car innovations are based on the engineer's creative act of invention. Too few of them are driven by the car user. Both OEMs and automotive suppliers must align their innovation management according to the customer requirements and future market trends. The product portfolio, the innovation marketing process, pricing policy, market research, close-to-market $\mathrm{R} \& \mathrm{D}$ centers, customer-segment innovations (i.e. brands, clusters, etc.) are all ways of improving customer and marketing orientation for auto-industry innovations.

\subsection{Active reshaping of the innovation portfolio}

An imbalance in the innovation portfolio leads to future growth gaps. OEMs and suppliers have to analyze and reshape their portfolios to gain a good balance of innovations in terms of potential and importance of innovations, strength and degree of innovativeness, external/internal innovations, timing, added value and profitability, customer segments, functional versus cost innovations, etc. The innovation portfolio must deliver short-term value as well as cover solid returns in existing or new fields of business in the future.

\subsection{Improvement of $R \& D$ economics and risk management}

To remain cost competitive, suppliers and OEMs must continuously improve their innovation economics. Three fields of action must be emphasized: Improvement in the efficiency of your $R \& D$ organization, i.e. reduction of the overall process costs and increases in productivity. Enhancement of your R\&D effectiveness, i.e. more and better innovations for your enterprise. And assessment of the future risks associated with new innovations for your company in order to protect your business from potential losses.

\subsection{Support of open organization and culture}

The auto sector must open up. It should embrace innovation trends from outside the industry, for example, from consumer electronics or telecommunications. OEMs and suppliers must also build innovation networks to enlarge their competencies and reduce costs. Management needs to create an open environment that strengthens a collaborative innovation culture, increases the competence level of its employees and supports entrepreneurial action in the R\&D department.

\subsection{Alignment of innovation strategy}

Suppliers and OEMs should regularly check their overall innovation strategy. The innovation proposition, the R\&D organization and culture, and the competence focus and level of collaboration must all be aligned to build a strong business case for OEMs or suppliers.

\section{CONCLUSION}

According to the authors of this article, innovation is a necessary activity in every industry, in every field of business. Ensure the competitiveness of businesses, customers are more interested in products and thereby improve economic performance. Innovation can take various forms. Innovation is linked to investments. In formulating the strategy is an important activity of senior management to determine, among other things, the innovation activities of the next period and the investment intensity. According to the authors' views, innovation is a necessity, the driving force for companies to keep or improved market position.

\section{REFERENCES}

Bessant, J., Pavitt, K., Tidd, J. (2007), Innovation management, Computer Press, ISBN 978-80-251-1466-7, Brno

Košturiak J., Chál' J. (2008), Innovation, your competitive advantage, Computer Press, ISBN 978-80-251-1929-7, Brno

Wyman, O. (2011), A comprehensive study on innovation in the automotive study, Available from: http://www.oliverwyman.com/pdf_files/CarInnovation2015 _engl.pdf, Accessed : 2011-10-01

***(2011),http://www.acea.be/images/uploads/pr/SK_Presentat ion_March20.pdf- Competitiveness and Prospects of the Slovak Automotive Industry in the EU, Accessed on: 2011$10-01$

***(2011),http://www.logistickymonitor.sk/en/images/prispevk y/uloha-inovacii.pdf, Accessed on: 2011-10-01

***(2011), http://www.euroekonom.sk/download2/ekonomikasr/Sektorova-analyza-Automobilovy-priemysel.pdf SARIO, Slovak Agency for Investment and Trade Development, Accessed on: 2011-10-01

***(2011),http://www.snt.sk/industries/automotive/Automotive .sk.php- S\&T, Accessed on: 2011-10-01

***(2011),http://www.springerlink.com/content/p7124ur63127 6324/, Small Business, Accessed on: 2011-10-01 